discharges were not only small in quantity, but at lengthened intervals, and attended with considerable pain, which had been the case for three years. It was evident constitutional treatment was indicated, independent of any application to the local enlargement ; I therefore commenced with giving the mistura ferri composita (L. P.) in the daytime, and two of the compound aloes pills (P. L.) at bedtime; this was more or less the constitutional treatment throughout, varied very slightly as circumstances might require. But to the local enlargement $I$ adopted the following novel plan:-Thaking a quantity of plaster of Paris, I made a mould of the nose, and whilst wet, I placed tapes in the plaster to secure it afterwards; the middle of one tape fastened to the mould was intended for securing it laterally by each end crossing the cheek on the same side, and tying together behind the neck; a second tape directed its course between the eyes over the centre of the os frontis, over the head, and secured to the first tape behind the neck; when sufficiently hard, the mould was removed, baked, and well seasoned with oil; when thus prepared it was replaced on the nose, and secured by the tapes so as to effect a gentle and equal pressure on the organ, the weight of the mould assisting, as it was made purposely rather thick, the lower part being left open to facilitate breathing. After wearing it in this manner a week, I found the mould much too large for the nose, and sat very loosely upon it. I was, therefore, certain the pressure had effected a considerable reduction in the size of the part affected: encouraged by this, a second mould was made on the reduced organ, which was ac. companied with the same satisfactory results; a third, fourth, and fifth mould followed, when the nose had assumed its natural size and appearance. On comparing the last with the first mould, the contrast was very striking, and would scarcely have been believed by any person who had not witnessed the process : each mould was worn about a fortnight, with the exception of the first and last; the former about a week; the latter was advised to be worn longer, and relinquished by degrees; the constitutional treatment succeeded in effecting menstruation regularly, and in a sufficient quantity. The nose still remains its natural size. I think this plan might be applied with advantage in many cases; the effect of pressure in chronic enlargements is well known; it is only the novel way of employing it that deserves attention in this case.

\section{BLACK OXIDE OF IRON.}

To the Editor of THE LANCET.

SIR,-Should no one be inclined to answer the interrogatories respecting the "black oxide of iron," having myself used it rather extensively for the last two years, a remark or two respecting it may not be wholly un. important to "Juvenis." The first time I tried it was on myself, for tic douloureux of the infra-orbital nerve, which vanished in three days. One other case was as decidedly relieved by it. I have seen phthisis, chlorosis, and other diseases of debility cured, if not alone by this ferruginous substance, it has been no inconsiderable auxiliary. One case of hypochondriasis (the chief symptom of which was hepatalgia) reco. vered in about six weeks, while taking " magnetic iron," without any adjunct, after having been subjected to mercurials, and other numerous remedies, for some years, without alleviation of uneasy feelings.

The dose I generally employ of the iron is four or six grains made into pills (by mixing powdered gum acacia, of which it requires a large quantity, and water). The dose is repeated according to the effect produced on the head, which is soon complained of by the patient.

It is said to have its activity increased by meeting with acid on the stomach. But, besides this action on the nerves, it is probable that metallic iron enters the blood in a minute state of division, or as a suboxide. Were an oxide to gain admission into the circulation, might not the electrical or vital action, always continuing, decompose it, and set the iron free, in the same manner as potassa will yield potassium and oxygen? Oxide and phosphate of iron are found in the blood out of the vessels. May not these changes take place after vitality has ceased, and especially when incinerated for testing? Proofs of decomposition taking place in the body are to be found, perhaps, most in the circulation. Salts of potassa, in combination with vegetable acids and nitrate of silver, are examples. Whether these hypotheses be correct or not, the preparation under consideration certainly deserves some attention. Your humble servant,

Middlesex Hospital, March 30, 1842.

Fr. Hoblyn.

STATISTICS OF LUNACY.

\section{MORTALITY AT THE WAKEFIELD} ASYLUM.

\section{To the Editor of 'THE LANCET.}

SrR,-It is much to be desired that some general system of statistical tables could be adopted in the annual statements of the public lunatic asylums in this kingdom. Numerous tables have been recently introduced by the different superintendents, reflecting great credit upon their own patient investigation, and highly interesting and useful : there are, however, some omissions which leave the public in the dark on several very important 
points. The following information should invariably be included, viz. :-

1. The daily average number of patients, and of the household respectively, for the year.

2. The number of cases readmitted from the commencement of the establishment.

3 . The various distinct causes of death from the commencement, exhibiting, of course, the instances of suicide, and the number of patients found dead in bed or e'sewhere,

4. The number of coroners' inquests, and the verdicts.

Moreover, it is especially important that a document, verifying, with the respective names and numbers of the patients, the cases in each table, should be annually drawn out and preserved, so that any of the tables can be readily and satisfactorily verified at any future period.

I have been much struck with the extraordinary mortality exhibited in the report of the Wakefield Asylum, just published, as follows:-

Patients admitted from the open-

ing of the institution........ 3006

Deduct readmitted cases...... 416

Total patients ....... $\mathbf{2 5 9 0}$

Total deaths ....... 966

I turned first, without success, to the report, and then to the supply of articles of diet, as shown in the statement of expenditure, supposing some explanation of the circumstance might possibly be found; but as the daily average number of persons maintained and the quantities consumed are not also shown, no inferences can be drawn from this source.

Without doubting the good management of the institution, I would be glad to receive, through your Journal, some information on this subject, that if there be any special sources of mortality in this institution they may be carefully guarded against in other establishments, whether supposed to arise from damp cells (as at the Dorchester A sylum), unsuitable diet, sedentary employments, confinement in restraint-chairs, solitary confinement, or other depressing causes. I have the honour to remain, Sir, your faithful and obedient servant,

Robert Gardiner Hill.

Lincoln, March 26, 1812.

\section{NOTE FROM MR. R. G. HILL.}

To the Editor of THE Lancer.

Srn,-To supply the omissions of the $e x$. parte statement in Dr. Cookson's letter published in the last LANCET, relative to the de- cease of Mr. M. in the Lincoln Asylum, I beg your insertion of the following letters, extracted from the minutes of the board. I have the honour to remain, \&c.

Robert Gardiner Hill.

Lincoln, A pril 10, 1842.

"Lincoln, March 8, 1812.

"Dear Sir,-I shall feel obliged if you will inform me whether you had mentioned the circumstances stated in your letter to Mr. Smith to any one before you were questioned by Mr. Smith at the time when you left the house. I am, dear Sir, \&c.

"To Mr. D. K."

$$
\text { "R. G. Hill, Surgeon. }
$$

$$
\text { "W-, March 10, } 1842 .
$$

" $\mathrm{Sir},-\mathrm{I}$ received your note, dated March 8 th, concerving having mentioned anything to any one concerning Mr. M. Mr. I., of $D$., one day came into the yard, after the death of Mr. M., and said that he (Mr. M.) was soon finished. He asked me if I knew anything concerning him. I told him I thought he was roughly handled; but, Sir, at that time my word was not to be taken, as you all well know. I was not in the room with them, neither did $I$ find any reason to say so from the treatment $I$ received from the keepers, as nothing of the kind was used towards me; but I heard an unusual noise, and at that time I was ready to set forth fancies for realities. I should be sorry in saying anything against the institution, as I am well convinced, from what $I$ have seen and experienced of it, that it is deserving of my highest praise. I am, yours truly,

$$
\text { “ To Mr. Hill." }
$$$$
\text { " D. K. }
$$

The craving appetite of Dr. Cookson for abuses in the Lincoln Asylum appears to be insatiate.

P.S.-Dr. James Johnson, smarting under the lash inflicted by "A Convert" in one of your late numbers, retorts in his own journal by calling non-restrainers mad, and their practice a humbug. I, who am a non-restrainer, will not retort by calling $\mathrm{Dr}$. Johnson mad, but should he ever become so, and experience the difference between the two modes of treatment, I predict that he will himself become "a convert."

* We know not where this controversy would stop if we did not suppress such comments as those which preceded the postscript of this letter,-fair enough between the parties perhaps, but not to the public. 